\title{
Whole Body Vibration on Drivers Seat and Fender with fully loaded Double Axle Tractor-Trailers under different Operating Conditions
}

\author{
MAN MOHAN DEO ${ }^{1 *}$, ADARSH KUMAR ${ }^{2}$ AND INDRA MANI ${ }^{3}$
}

\begin{abstract}
Tractor is used for agricultural operations and as a common means of transportation in rural areas. It exposes the drivers and workers sitting on fenders to whole body vibration, which results into back pain, spine degeneration and even spine disc problems. A study was carried out to measure the whole-body vibration on driver and fender seat with fully loaded double axle tractor-trailer under different operating conditions. Vibration was measured on two terrains (Asphalt and Farm), at three speed $(10,12,14 \mathrm{~km} / \mathrm{h}$ on asphalt terrain and 4, 5, $7 \mathrm{~km} / \mathrm{h}$ on farm terrain, in three directions (longitudinal, transverse, and vertical). Data were recorded for $120 \mathrm{~s}$ each and analyzed using vibration meter and analyzer for three replications of each treatments. Vector sum of vibration and Health Guidance Caution Zone upper and lower limit were obtained for different operating conditions to know the health effect of vibration. The magnitude of whole-body vibration on driver seat on asphalt terrain and farm terrain varied from $0.257 \mathrm{~m} / \mathrm{s}^{2}$ to $0.376 \mathrm{~m} / \mathrm{s}^{2}$ and 0.273 to $0.438 \mathrm{~m} / \mathrm{s}^{2}$ at 10 and $14 \mathrm{~km} / \mathrm{h}$ and 4 and $7 \mathrm{~km} / \mathrm{h}$ speed in longitudinal (X-axis) direction respectively. Whereas, in vertical direction (Z-axis) on asphalt and farm terrain it varied from 0.373 to $0.552 \mathrm{~m} / \mathrm{s}^{2}$ and 0.389 to $0.590 \mathrm{~m} / \mathrm{s}^{2}$ at 10 to $14 \mathrm{~km} / \mathrm{h}$ and 4 to $7 \mathrm{~km} / \mathrm{h}$ speed respectively. On fenders, it varied in the range of $0.400-$ $0.629 \mathrm{~m} / \mathrm{s}^{2}$, and $0.427-1.60 \mathrm{~m} / \mathrm{s}^{2}$ in longitudinal and vertical direction respectively on asphalt terrain, whereas on farm terrain in longitudinal and vertical direction it varied from 0.321 to $0.903 \mathrm{~m} / \mathrm{s}^{2}$ and 0.608 to $0.801 \mathrm{~m} / \mathrm{s}^{2}$ respectively. In all position, transverse direction(Y-axis) vibration magnitude was negligible compared to other two directions. With increase in speed vibration magnitude increased. Vibration magnitude lied in the little uncomfortable to fairly uncomfortable range. More than $2 \mathrm{~h}$ of exposure of vibration at driver seat and fenders will increase the chance of health effects as per health guidance caution zone of ISO-2631-1:1997.
\end{abstract}

KEYWORDS

Tractor, trailer, vibration, magnitude, health

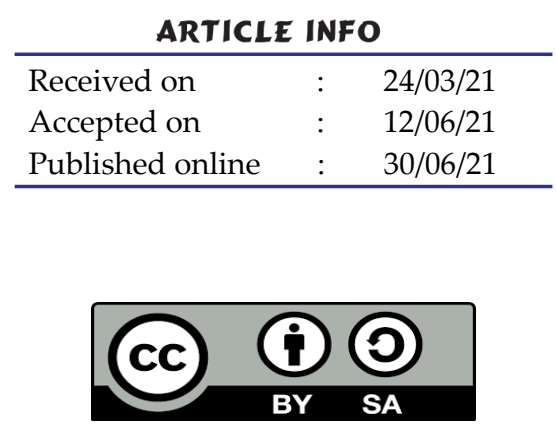

\section{INTRODUCTION}

$\mathrm{I}$ ndian agriculture growth is immensely contributed by the mechanization specially the tractorization of Indian agriculture. India tops in the manufacturing of the tractor in the world and tractor production has increased multi-folds from only 880 tractors in 1961 to a record production of 7.97 lakh tractors in 2017-18 (Anonymous, 2018). Tractors played an important role in Indian agriculture, and the growth of agriculture followed a similar trend as growth in mechanization. Tractors are used for agricultural operations and as a common means of transportation in rural areas. Singh (2001) reported that tractor is used mostly used for transport activities and accounted for about 60 percent of the average annual use of 600 hours. But it also exposes the drivers, workers sitting on fenders after loading and unloading to vibration. There are different workplaces of high exposure of vibration, including driver seat on agricultural tractors, construction machines and transportation vehicles (Smith and Leggat, 2005). The long-term exposure to the Whole Body Vibra- tion (WBV) has drastic effects on the human health. It may cause several health problems like back pain, spine degeneration and spine disc disease as reported by Hulshof and van Zanten (1987) Bovenzi and Hulshof (1999) ; Kumar et al (2001). The symptom of low back pain has been found prevalent in workers exposed to WBV in comparison to those workers not exposed to WBV (Boshuizen et al, 1990; Bovenzi and Betta, 1994). Tractors do not have suspension systems and vibrations levels are high in comparison to other road vehicles. It becomes more critical since the dominant natural frequencies $(1-7 \mathrm{~Hz})$ of tractor lies within the critical frequency range of human body, e.g., human trunk and human vertebra have a natural frequency of 4-8 and 4-5 Hz, respectively . Boshuizen et al (1990) reported the prevalence of back pain in tractor drivers and found that it was $10 \%$ higher in workers exposed to vibration compared to workers not exposed to vibration. Prevalence of back pain amplified with the vibration dose. Boshuizen et al (1992) studied the long-term health effect of whole-body vibration; on the drivers and workers

\footnotetext{
1 Ph.D Scholar, Div. of Agricultural Engineering, ICAR Indian Agricultural Research Institute, New Delhi, India

2 Principal Scientist, Div. of Agricultural Engineering, ICAR Indian Agricultural Research Institute, New Delhi, India

${ }^{3}$ Head, Div. of Agricultural Engineering, ICAR Indian Agricultural Research Institute, New Delhi, India

${ }^{*}$ Corresponding author email: anandi888@gmail.com
} 
of fork-lift trucks and freight-container tractors based on a questionnaire. During a representative working period (vector sum of the frequency weighted acceleration in the $x, y$, and $z$-directions) vibration level was $0.8 \mathrm{~m} / \mathrm{s}^{2}$ for the forklift trucks and $1.0 \mathrm{~m} / \mathrm{s}^{2}$ for freight-container tractors. Of the young (<35 years), short-term-exposed drivers, 68\% reported that they had back pain regularly vs. only $25 \%$ of the reference group of comparable age. Vibration induced damage caused by cumulative effect of magnitude, frequency, duration of exposure of vibration.

In India two types of tractor-trailers are used namely; single axle tractor-trailers and double axle tractor trailers. Scarcely any study is available to know the effect of whole-body vibration on the workers sitting on fenders and drivers' seat while transportation with double-axle tractor-trailers. Keeping this in view, the present study was carried out to measure the magnitude of whole-body vibration in tractor seat and fenders when attached with fully loaded double-axle tractortrailer, with the purpose to investigate the health effects as per the ISO (1997) standard.

\section{MATERIALS AND METHODS}

The Whole-Body Vibration (WBV) study was carried out on a $39 \mathrm{hp}$ tractor with fully loaded double axle tractor-trailer $(7400 \mathrm{~kg})$ (Figure 1) at the farm and terrains of ICAR-Indian Agricultural Research Institute, New Delhi. The study was carried out on two types of terrain namely; asphalt terrain and farm terrain (Figure 2 ) at three speed $(10,12,14 \mathrm{~km} / \mathrm{h}$ on asphalt terrain and 4,5 , and $7 \mathrm{~km} / \mathrm{h}$ on farm terrain as per ISO5008(1979)). WBV was measured using seat pad accelerometers on driver seat and tri-axial accelerometers on fenders of tractor (Figure 3 ). The vibration was measured for $120 \mathrm{sec}-$ onds and three replications were taken for each treatment. The experiment was conducted as per plan of experiment mentioned in Table 1. Data were stored and analyzed using the AdVibra vibration meter and analyzer (Figure 3 ). Vibration magnitude was measured in three directions namely; longitudinal (X-axis), transverse (Y-axis), and vertical direction (Z-axis). Then, Vector sum of vibration was calculated by taking frequency weightings $(\mathrm{kx}=1.4, \mathrm{ky}=1.4$ and $\mathrm{kz}=1)$, which was further used to calculate the Health Guidance Caution Zones (HGCZ) as per the ISO-2631-1:1997. With values of 6 $\mathrm{m} / \mathrm{s}^{2}$ and $3 \mathrm{~m} / \mathrm{s}^{2}$ as upper and lower boundary limits of caution zone, time exposure was calculated (Kumar et al, 2001).
Table 1: Experimental plan for whole-body vibration measurement

\begin{tabular}{|c|c|c|}
\hline \multicolumn{2}{|c|}{ Independent variables } & \multirow{4}{*}{$\begin{array}{l}\text { Dependent } \\
\text { variables } \\
\text { Vibration } \\
\text { magnitude a) } \\
\text { Longitudinal } \\
\text { (X-axis) b) } \\
\text { Transverse } \\
\text { (Y-axis) c) } \\
\text { Vertical } \\
\text { (Z-axis) }\end{array}$} \\
\hline $\begin{array}{l}\text { Types of } \\
\text { terrain (2) }\end{array}$ & Asphalt, Farm & \\
\hline Speed (3) & $\begin{array}{l}\text { Asphalt road: } 10,12,14 \mathrm{~km} / \mathrm{h} \\
\text { Farm road: } 4,5 \text {, and } 7 \mathrm{~km} / \mathrm{h}\end{array}$ & \\
\hline $\begin{array}{l}\text { Double axle } \\
\text { Trailer }\end{array}$ & Full (7400 kg) & \\
\hline $\begin{array}{l}\text { Accelerometer } \\
\text { Position (3) }\end{array}$ & $\begin{array}{l}\text { Driver, Right Fender, and Left } \\
\text { Fender }\end{array}$ & \\
\hline
\end{tabular}

\section{Weighted r.m.s acceleration}

The weighted r.m.s acceleration was measured as per the method discussed in IS0-2631-1:1997. The weighted r.m.s acceleration is expressed in meters per second squared $\left(\mathrm{m} / \mathrm{s}^{2}\right)$ for translational vibration (Kumar et al, 2001). $a_{w}=\left[\frac{1}{T} \int_{0}^{T} a_{w}^{2}(t) d t\right]^{1 / 2}$

The weighted acceleration (Translational) as a function of time (time history) in $\mathrm{m} / \mathrm{s}^{2}, \mathrm{~T}=$ Duration of the measurement in seconds.

\section{Health guidance zone as per ISO-2631-1-1997}

Exposure durations at upper limits of cautions zone were calculated as (Kumar et al, 2001):

$\mathrm{T}_{u}=1 / 6\left[\mathrm{~T}_{6} / \mathrm{a}_{v}\right]^{2}$

where $T_{6}$ is $6 \mathrm{~m} / \mathrm{s}^{2} \mathrm{rms}$ acceleration for 1-10 minute of health caution zone.

Exposure durations at lower limits of cautions zone was calculated as:

$\mathrm{T}_{l}=1 / 6\left[\mathrm{~T}_{3} / \mathrm{a}_{v}\right]^{2}$

where $T_{3}$ is $3 \mathrm{~m} / \mathrm{s}^{2} \mathrm{rms}$ acceleration for $1-10$ minute of health caution zone.

Overall vibration acceleration above the upper boundary indicates the likeliness of health risks and below the lower boundary indicates no health effects. As per ISO-2631-1-1997 the comfort reactions to vibration environments are mentioned in Table 2 . Vibration magnitude below $0.315 \mathrm{~m} / \mathrm{s}^{2}$ is not uncomfortable and higher than $2 \mathrm{~m} / \mathrm{s}^{2}$ is extremely uncomfortable. 

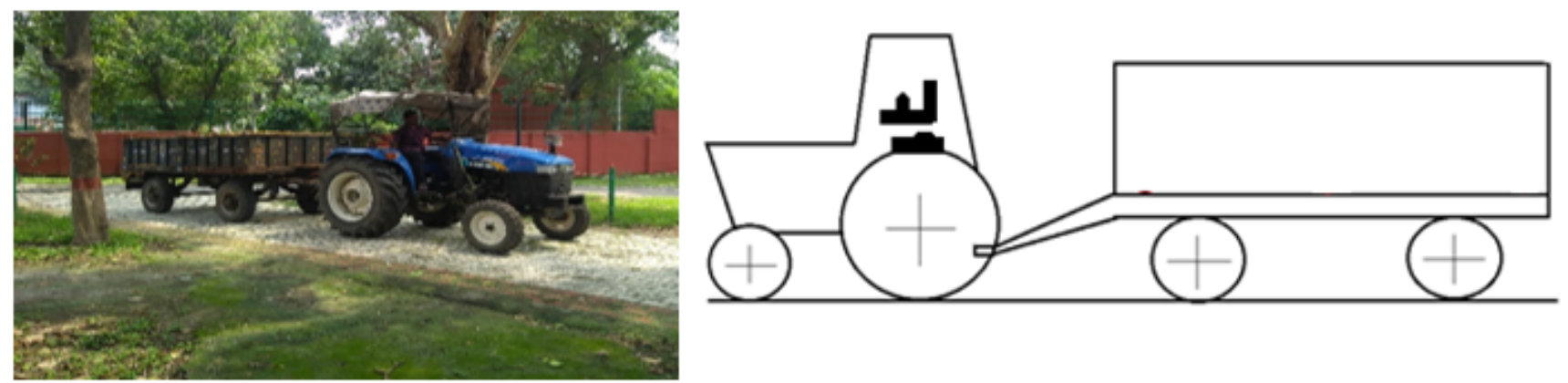

Fig. 1: Tractor with double axle trailer and positions of accelerometers

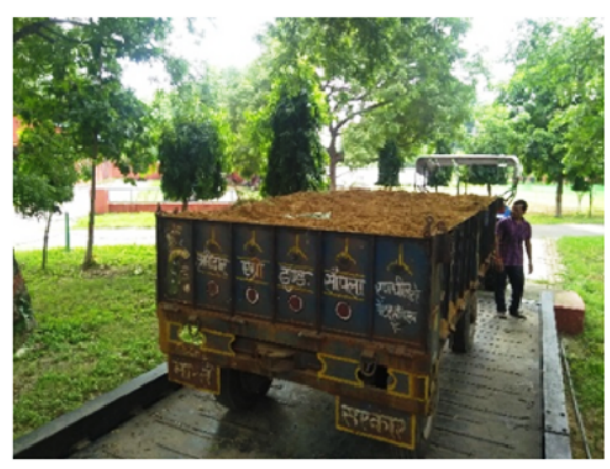

Fully loaded double axle trailer

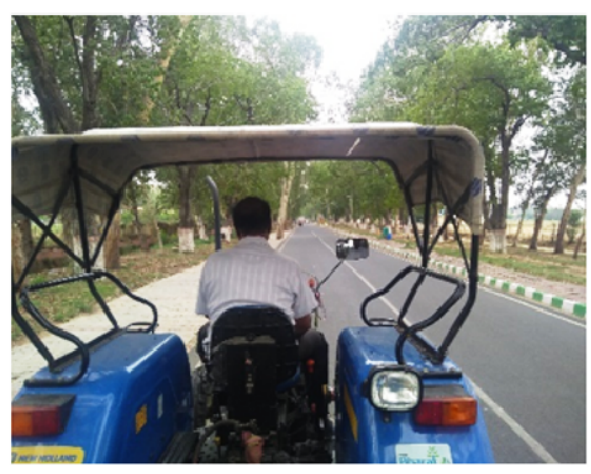

Asphalt terrain

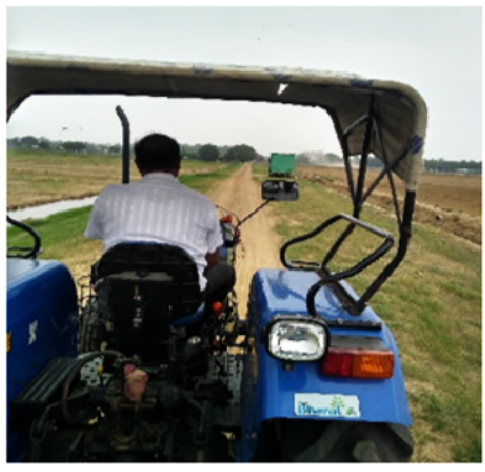

Farm terrain

Fig. 2: Fully loaded double axle tractor-trailer and terrain conditions

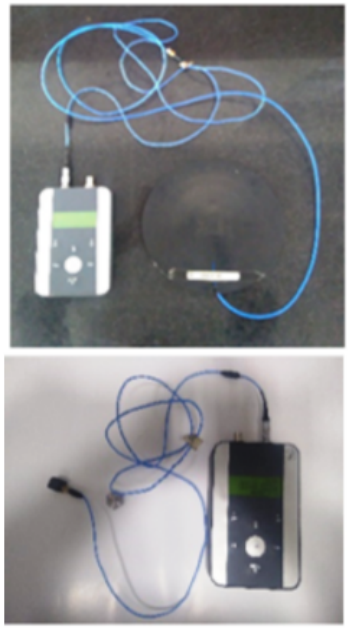

Vibration meter and analyzer

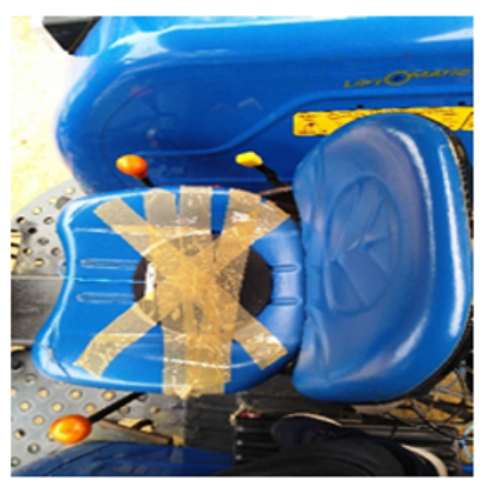

Tri-axial seat pad accelerometer

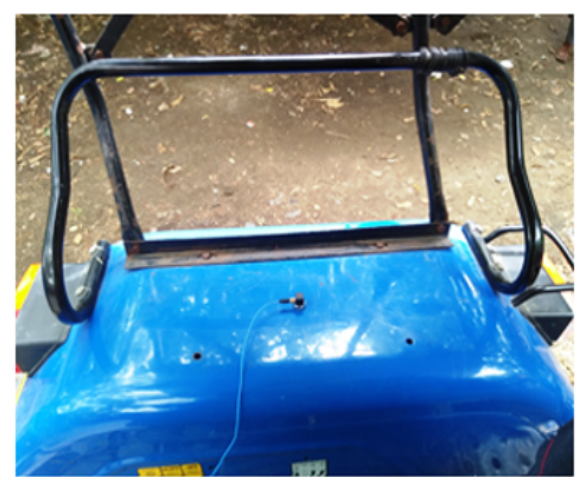

Tri-axial accelerometer

Fig. 3: Vibration measurement system for tractor driver seat andfenders 
Table 2: Comfort reactions to vibration environments as per ISO-2631-1-1997

\begin{tabular}{ll}
\hline $\begin{array}{l}\text { Vibration values } \\
<0.315 \mathrm{~m} / \mathrm{s}^{2}\end{array}$ & Comfort reactions \\
$0.315 \mathrm{~m} / \mathrm{s}^{2}$ to $0.63 \mathrm{~m} / \mathrm{s}^{2}$ & A little uncomfortable \\
$0.5 \mathrm{~m} / \mathrm{s}^{2}$ to $1 \mathrm{~m} / \mathrm{s}^{2}$ & Fairly uncomfortable \\
$0.8 \mathrm{~m} / \mathrm{s}^{2}$ to $1.6 \mathrm{~m} / \mathrm{s}^{2}$ & uncomfortable \\
$1.25 \mathrm{~m} / \mathrm{s}^{2}$ to $2.5 \mathrm{~m} / \mathrm{s}^{2}$ & Very uncomfortable \\
$>2 \mathrm{~m} / \mathrm{s}^{2}$ & Extremely uncomfortable \\
\hline
\end{tabular}

\section{RESULTS AND DISCUSSION}

The Whole-Body Vibration (WBV) was measured on different terrains conditions, at three different speed at driver seat and right and left fender of tractor with fully loaded doubleaxle tractor-trailers. The vibration was measured in three directions and vector sum of vibration was obtained. Further upper and lower Health Guidance Caution Zones (HGCZ) were found to know the exposure duration and its health effect on the human body as per ISO-2631-1:1997.

\section{Magnitude of vibration and Health Guidance Caution Zones (HGCZ) on driver seat}

The magnitude of vibration on driver seat on asphalt terrain varied from $0.257 \mathrm{~m} / \mathrm{s}^{2}$ to $0.376 \mathrm{~m} / \mathrm{s}^{2}$ at 10 and $14 \mathrm{~km} / \mathrm{h}$ speed in longitudinal (X-axis) direction. Whereas, it varied from 0.373 to $0.552 \mathrm{~m} / \mathrm{s}^{2}$ at 10 to $14 \mathrm{~km} / \mathrm{h}$ in vertical direction(Zaxis). With increase in speed vibration magnitude increased in both longitudinal and vertical direction. In transverse direction(Y-axis) it was negligible compared to both the direction (Table 3 ). On farm terrain, magnitude varied from 0.273 to $0.438 \mathrm{~m} / \mathrm{s}^{2}$ in longitudinal direction and 0.389 to $0.590 \mathrm{~m} / \mathrm{s}^{2}$ in vertical direction at 4 and $7 \mathrm{~km} / \mathrm{h}$. Similar to asphalt terrain with increase in speed vibration magnitude increased in longitudinal and vertical direction in farm terrain. On asphalt terrain Health Guidance Caution Zone (HGCZ) showed that at $14 \mathrm{~km} / \mathrm{h}$ even on exposure of $1.77 \mathrm{~h}$ health effect will start and after more than $7.11 \mathrm{~h}$ exposure there will be certain health effect on the driver of the tractor. Similar results of HGCZ on farm terrain showed that even at lower speed of 7 $\mathrm{km} / \mathrm{h}$ compared to asphalt terrain, health effect will start at more than $1.5 \mathrm{~h}$ exposure and certain health exposure will be there when it will be higher than $6 \mathrm{~h}$ (Table 3 ).

Table 3: Magnitude of vibration and health guidance caution zones under different conditions at driver seat

\begin{tabular}{|c|c|c|c|c|c|c|}
\hline \multicolumn{7}{|c|}{ Asphalt terrain } \\
\hline Speed & $\mathbf{a} \mathbf{w}_{\mathbf{x}}, \mathbf{m} / \mathbf{s}^{2}$ & $a w_{y}, m / s^{2}$ & $\mathbf{a w}_{\mathbf{z}}, \mathbf{m} / \mathbf{s}^{2}$ & $\begin{array}{r}\text { Total value, } \\
\mathbf{a}_{v}, \mathbf{m} / \mathbf{s}^{2}\end{array}$ & $\begin{array}{c}\text { Upper limit of } \\
\text { HGCZ, h }\end{array}$ & $\begin{array}{r}\text { Lower limit of } \\
\text { HGCZ, h }\end{array}$ \\
\hline $10 \mathrm{~km} / \mathrm{h}$ & 0.257 & 0.0842 & 0.373 & 0.719 & 11.603 & 2.901 \\
\hline $12 \mathrm{~km} / \mathrm{h}$ & 0.296 & 0.0843 & 0.522 & 0.841 & 8.4810 & 2.120 \\
\hline $14 \mathrm{~km} / \mathrm{h}$ & 0.376 & 0.0843 & 0.552 & 0.918 & 7.115696 & 1.775 \\
\hline \multicolumn{7}{|c|}{ Farm Terrain } \\
\hline $4 \mathrm{~km} / \mathrm{h}$ & 0.273 & 0.0843 & 0.389 & 0.741 & 10.928 & 2.732 \\
\hline $5 \mathrm{~km} / \mathrm{h}$ & 0.336 & 0.0843 & 0.491 & 0.852 & 8.264 & 2.066 \\
\hline $7 \mathrm{~km} / \mathrm{h}$ & 0.438 & 0.0843 & 0.590 & 0.989 & 6.125 & 1.531 \\
\hline
\end{tabular}

Where, $\mathrm{aw}_{x}, \mathrm{aw}_{y}, \mathrm{aw}_{z}$ are the weighted r.m.s. accelerations with respect to the orthogonal axes $\mathrm{x}, \mathrm{y}, \mathrm{z}$ respectively, and $\mathrm{a}_{v}=\mathrm{Vibration}_{\mathrm{b}}$ total value of weighted acceleration value

\section{Magnitude of vibration and Health Guidance Caution Zones (HGCZ) on left fender}

On asphalt terrain magnitude of vibration on left fender varied from 0.400 to $0.629 \mathrm{~m} / \mathrm{s}^{2}$ in longitudinal direction while it varied from 0.427 to $1.60 \mathrm{~m} / \mathrm{s}^{2}$ at 10 and $14 \mathrm{~km} / \mathrm{h}$ in vertical direction. With increase in speed vibration magnitude increased in vertical direction. HGCZ showed that lower limit of $0.76 \mathrm{~h}$ and upper limit of $3 \mathrm{~h}$. Which indicated that health effect on left fender will start after $0.76 \mathrm{~h}$ of travel and cer- tain health damage will be there on more than $3 \mathrm{~h}$ exposure. On farm terrain, magnitude of vibration varied from 0.321 to $0.557 \mathrm{~m} / \mathrm{s}^{2}$ at 4 and $7 \mathrm{~km} / \mathrm{h}$ speed in longitudinal direction and 0.618 to $0.726 \mathrm{~m} / \mathrm{s}^{2}$ in vertical direction at speed of 4 and $7 \mathrm{~km} / \mathrm{h}$. With increase in speed vibration magnitude was increased. Exposure of $1 \mathrm{~h}$ will start the health damage and more that $4 \mathrm{~h}$ will have certain health damage as per HGCZ (Table 4 ). 
Table 4: Magnitude of vibration and health guidance caution zones under different conditions at fenders

Health Guidance Caution Zones (HGCZ) as per ISO-2631-1-1997

Asphalt terrain, Left fender

\begin{tabular}{|c|c|c|c|c|c|c|}
\hline Speed & $\mathbf{a} \mathbf{w}_{x}, \mathbf{m} / \mathbf{s}^{2}$ & $\mathbf{a w}_{y}, \mathbf{m} / \mathbf{s}^{2}$ & $\mathbf{a w}_{z}, \mathbf{m} / \mathbf{s}^{2}$ & $\begin{array}{c}\text { Total value, } \mathbf{a}_{v} \\
\mathbf{m} / \mathbf{s}^{2}\end{array}$ & $\begin{array}{c}\text { Upper limit of } \\
\text { HGCZ, h }\end{array}$ & $\begin{array}{c}\text { Lower limit of } \\
\text { HGCZ, h }\end{array}$ \\
\hline $10 \mathrm{~km} / \mathrm{h}$ & 0.629 & 0.085 & 0.427 & 1.103 & 4.933 & 1.233 \\
\hline $12 \mathrm{~km} / \mathrm{h}$ & 0.400 & 0.085 & 0.716 & 1.021 & 5.751 & 1.438 \\
\hline $14 \mathrm{~km} / \mathrm{h}$ & 0.422 & 0.085 & 1.606 & 1.403 & 3.046 & 0.762 \\
\hline \multicolumn{7}{|c|}{ Farm terrain, left fender } \\
\hline $4 \mathrm{~km} / \mathrm{h}$ & 0.321 & 0.085 & 0.618 & 0.913 & 7.195 & 1.799 \\
\hline $5 \mathrm{~km} / \mathrm{h}$ & 0.404 & 0.088 & 0.711 & 1.023 & 5.736 & 1.434 \\
\hline $7 \mathrm{~km} / \mathrm{h}$ & 0.557 & 0.085 & 0.726 & 1.161 & 4.451 & 1.113 \\
\hline
\end{tabular}

Where, $\mathrm{aw}_{x}, \mathrm{aw}_{y}, \mathrm{aw}_{z}$ are the weighted r.m.s. accelerations with respect to the orthogonal axes $\mathrm{x}, \mathrm{y}, \mathrm{z}$ respectively, and $\mathrm{a}_{v}=\mathrm{Vibration}_{\mathrm{b}}$ total value of weighted acceleration value

Magnitude of vibration and Health Guidance Caution Zones (HGCZ) on right fender

Vibration magnitude was measured on right fender on asphalt and farm terrain. The result showed that on asphalt terrain in longitudinal direction, vibration varied from 0.475 to $0.525 \mathrm{~m} / \mathrm{s}^{2}$ at $10-14 \mathrm{~km} / \mathrm{h}$ speed. In vertical direction, it varied from 0.507 to 0.891 at 10 and $14 \mathrm{~km} / \mathrm{h}$ speed. With increase in speed vibration magnitude increased. Health effect was studied in terms of HGCZ and it was found that lower limit 1 $\mathrm{h}$ and upper limit of $4 \mathrm{~h}$, which inferred that even more than 1 $h$ exposure will start health effect and upon exposure of more that $4 \mathrm{~h}$ there will be certain health effect on asphalt terrain (Table 5 ). On farm terrain, vibration magnitude varied from 0.554 to $0.903 \mathrm{~m} / \mathrm{s}^{2}$ in longitudinal direction and 0.608 to 0.801 $\mathrm{m} / \mathrm{s}^{2}$ in vertical direction. HGCZ observation showed that even at less than $1 \mathrm{~h}$ health damage will start and exposure of $2.5 \mathrm{~h}$ will have certain health effect on the worker sitting on the right fender of the tractor (Table 5 ).

Table 5: Magnitude of vibration and health guidance caution zones under different conditions at fenders

\begin{tabular}{|c|c|c|c|c|c|c|}
\hline \multicolumn{7}{|c|}{ Health Guidance Caution Zones (HGCZ) as per ISO-2631-1-1997 } \\
\hline \multicolumn{7}{|c|}{ Asphalt terrain, right fender } \\
\hline Speed & $\mathbf{a w}_{x}, \mathbf{m} / \mathbf{s}^{2}$ & $\mathbf{a w} y, \mathbf{m} / \mathbf{s}^{2}$ & $\mathbf{a w}_{z}, \mathbf{m} / \mathbf{s}^{2}$ & $\begin{array}{r}\text { Total value, } \\
\mathbf{a}_{v}, \mathbf{m} / \mathbf{s}^{2}\end{array}$ & $\begin{array}{c}\text { Upper limit of } \\
\text { HGCZ, h }\end{array}$ & $\begin{array}{r}\text { Lower limit of } \\
H G C Z, h\end{array}$ \\
\hline $10 \mathrm{~km} / \mathrm{h}$ & 0.475 & 0.085 & 0.507 & 0.981 & 6.230 & 1.558 \\
\hline $12 \mathrm{~km} / \mathrm{h}$ & 0.525 & 0.085 & 0.631 & 1.089 & 5.062 & 1.266 \\
\hline $14 \mathrm{~km} / \mathrm{h}$ & 0.489 & 0.085 & 0.891 & 1.172 & 4.370 & 1.093 \\
\hline \multicolumn{7}{|c|}{ Farm terrain, right fender } \\
\hline $4 \mathrm{~km} / \mathrm{h}$ & 0.903 & 0.085 & 0.801 & 1.553 & 2.487 & 0.622 \\
\hline $5 \mathrm{~km} / \mathrm{h}$ & 0.554 & 0.085 & 0.608 & 1.106 & 4.904 & 1.226 \\
\hline $7 \mathrm{~km} / \mathrm{h}$ & 0.700 & 0.085 & 0.712 & 1.298 & 3.559 & 0.890 \\
\hline
\end{tabular}

Where, $\mathrm{aw}_{x}, \mathrm{aw}_{y}, \mathrm{aw}_{z}$ are the weighted r.m.s. accelerations with respect to the orthogonal axes $\mathrm{x}, \mathrm{y}, \mathrm{z}$ respectively, and $\mathrm{a}_{v}=\mathrm{Vibration}$ total value of weighted acceleration value

\section{CONCLUSIONS}

Vibration measurement on different positions of driver's seat and fender seat under different operating conditions showed that

1. Exposure of vibration of less than $2 \mathrm{~h}$ will start effect on the health and more than $6 \mathrm{~h}$ exposure will certainly affect the health of the driver during transportation with fully loaded double-axle tractor trailers on asphalt and farm terrain.

2. Magnitude of vibration on driver seat on asphalt and farm terrains lied in the zone of little uncomfortable to fairly uncomfortable as per ISO-2631-1:1997. 
3. On right and left fenders, even exposure of less than $1 \mathrm{~h}$ will start effect on the health of workers sitting there and exposure of $3 \mathrm{~h}$ will have certain health effect.

\section{REFERENCES}

Anonymous 2018. Agricultural statistics at a glance. Ministry of Agriculture and farmer's welfare, Government of India.

Boshuizen HC, Bongers PM and Hulshof CTJ. 1990. Self-reported back pain in tractor drivers exposed to whole-body vibration. International Archives of Occupational and Environmental Health 62(2):109-115. url: https://dx.doi.org/10.1007/bf00383586. doi: 10.1007/bf00383586

Boshuizen HC, Bongers PM and Hulshof CTJ. 1992. Self-Reported Back Pain in Fork-Lift Truck and Freight-Container Tractor Drivers Exposed to Whole-Body Vibration. Spine 17(1):5965. url: https://dx.doi.org/10.1097/00007632-199201000-00010. doi: 10.1097/00007632-199201000-00010

Bovenzi M and Betta A. 1994. Low-back disorders in agricultural tractor drivers exposed to whole-body vibration and postural stress. Applied Ergonomics 25(4):231-241. url: https://dx.doi. org/10.1016/0003-6870(94)90004-3. doi: 10.1016/0003-6870(94) 90004-3

Bovenzi M and Hulshof CTJ. 1999. An updated review of epidemiologic studies on the relationship between exposure to whole-
4. Magnitude of vibration on right and left fenders lied in the zone of a little uncomfortable to uncomfortable range as per ISO-2631-1:1997.

body vibration and low back pain (1986-1997). International Archives of Occupational and Environmental Health 72(6):351-365. url: https://dx.doi.org/10.1007/s004200050387. doi: 10.1007/ s004200050387

Hulshof C and van Zanten BV. 1987. Whole-body vibration and low-back pain. International Archives of Occupational and Environmental Health 59(3):205-220. url: https://dx.doi.org/10.1007/ bf00377733. doi: 10.1007/bf00377733

ISO 1997. ISO 2631-1:1997 Evaluation of human exposure to wholebody vibration- Part 1: general requirements.

Kumar A, Mahajan P, Dinesh M and Varghese M. 2001. Tractor vibration severity and driver health: a study from rural India. $J$. Agric. Engg. Res. 80(4):313-328. doi: doi:10.1006/jaer.2001.0755

Singh G. 2001. Relationship between Mechanization and Agricultural Productivity in Various Parts of India. . Agricultural Mechanization in Asia Africa and Latin America 32(2):68-76.

Smith D and Leggat PA. 2005. Whole-body vibration: health effects, measurement and minimization. Professional Safety 50:35-40.

Citation:

Deo MM, Kumar A and Mani I. 2021. Whole Body Vibration on Drivers Seat and Fender with fully loaded Double Axle Tractor-Trailers under different Operating Conditions. Journal of AgriSearch 8(2): 149-154 